\title{
Las relaciones de poder en la Educación Superior desde un enfoque de género: mecanismos de inclusión, exclusión y resistencias
}

Power relationships in higher education from the gender perspective: inclusion, exclusion, and resistance mechanisms

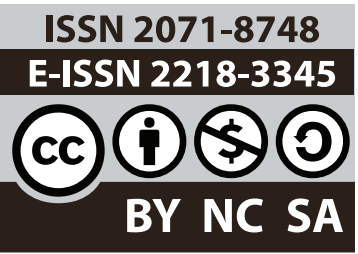

URI: http://hdl.handle.net/11298/900

DOI: http://dx.doi.org/10.5377/entorno.v0i66.6737
Ana Esther Mamani-Colque ORCID: 0000-0003-4492-2042

Gladys Merma-Molina ORCID: 0000-0002-9856-6314 Universidad Mayor de San Simón (Bolivia) Universidad de Alicante (España) anaesthermamani@gmail.com

Recibido: 17/08/18 Aprobado: 12/12/18

\section{Resumen}

El objetivo general del estudio es comprender y analizar qué tipo de relaciones de poder se desarrollan en la Universidad Boliviana. Se adoptó el enfoque cualitativo que permite recrear en la interacción social y simbólica, ensamblando la voz de los actores. La muestra tiene un carácter intencional no probabilístico, habiéndose efectuado un total de 80 entrevistas a docentes y autoridades universitarias. Se ha diseñado una guía semiestructurada de entrevistas en profundidad y cuadros de observación para el registro etnográfico. Se concluye que las académicas se desenvuelven de forma diferente que los docentes en la gestión y en la política universitaria; su desempeño profesional está marcado por tres tipos de mecanismos: de inclusión, de exclusión y de resistencias, con claro predominio del segundo. Los factores que

\section{Abstract}

The general objective of the study is to understand and analyze what kind of power relations are developed in the Bolivian University. The qualitative approach was adopted that allows recreating social and symbolic interaction, assembling the voice of the actors. The sample has a non-probabilistic intentional character, having conducted a total of 80 interviews with teachers and university authorities. A semi-structured guide of in-depth interviews and observation charts has been designed for the ethnographic record. It is concluded that academic women perform differently than teachers in university management and policy. Three types of mechanisms mark their professional performance: inclusion, exclusion, and resistance, with a clear predominance of the latter. The factors that determine the functioning of 
determinan el funcionamiento de estos mecanismos son la cultura organizacional androcéntrica de la universidad, el contexto familiar y la propia subjetividad de las docentes. Prevalece consistentemente el habitus del "deber ser mujer-esposa-madre-profesional-ama de casa" que configura la ideología vigente de la multifuncionalidad de la mujer. En suma, hay poder activo y real de los hombres y otro poder pasivo de las mujeres que plantea la necesidad de hacer una crítica de la posición que ocupan hombres y mujeres, y de las valoraciones subjetivas que las personas y los colectivos tienen acerca de las relaciones de poder en el contexto universitario.

\section{Palabras clave}

Educación superior; Sexismo; Planes de estudio; Violencia contra la mujer; Desigualdad social. these mechanisms are the androcentric organizational culture of the university, the family context, and the subjectivity of the teachers themselves. The habitus of "having to be a woman-wife-mother-professionalhome mistress" that configures the current ideology of women's multifunctionality prevails consistently. In short, there is active and real power of men and another passive power of women that raises the need to make a critique of the position occupied by men and women, and of the subjective valuations that people and collectives have about power relations in the university context.

\section{Keywords}

Higher education, Sexism, Study programs, Violence against women, Social inequality.

\section{Introducción}

Las redes de poder dentro del espacio universitario boliviano son un complejo entramado de mecanismos visibles e invisibles de inclusión, exclusión y resistencias en las que han predominado los hombres. Si bien en este espacio académico-institucional la presencia de la mujer se ha ido incrementando cuantitativamente, continúan manteniéndose prácticas sociohistóricas androcentristas, con características relacionales en las que se perpetúan los discursos e imaginarios de inequidad de género en detrimento de lo femenino.

En los últimos años, las carreras tradicionalmente masculinizadas están siendo pobladas por mujeres y en las denominadas carreras feminizadas se evidencia también la presencia de un mayor porcentaje de hombres. Este mismo fenómeno ocurre en el estamento docente donde las mujeres tienen cada vez una mayor presencia. Aún así, las docentes, a día de hoy, representan porcentajes significativamente reducidos respecto a sus pares masculinos, situación que se incrementa sobre todo en puestos de mayor jerarquía. La Universidad Mayor de San Simón (UMSS), una de las instituciones universitarias más antiguas y de mayor prestigio en el ámbito boliviano, fundada el 5 de noviembre de 1830, es un reflejo de lo que ocurre en los demás centros de estudios superiores.

Los últimos datos estadísticos con los que se cuenta, reflejado en la Universidad en Cifras (2014), muestra la existencia de desequilibrios por razón de género. Así, del total de 1,667 docentes de la UMSS, 1,133 son hombres (67.97\%), de los cuales 238 son a dedicación exclusiva y 895 a dedicación parcial, mientras que 534 son mujeres (32.03\%), siendo 109 de ellas a dedicación exclusiva y 425 a dedicación parcial (Tabla 1). 
Tabla 1. Diferenciales de género en la docencia universitaria UMSS (2014)

\begin{tabular}{|c|c|c|c|c|c|c|c|}
\hline \multirow{2}{*}{ FACULTAD } & \multirow{2}{*}{$\begin{array}{l}\text { TOTAL } \\
\text { DOCENTES } \\
\text { AÑO } 2014\end{array}$} & \multicolumn{2}{|c|}{$\begin{array}{r}\text { DEDICACIÓN } \\
\text { EXCLUSIVA }\end{array}$} & \multirow{2}{*}{$\begin{array}{l}\text { TOTAL DED. } \\
\text { EXCL. }\end{array}$} & \multicolumn{2}{|c|}{$\begin{array}{l}\text { DEDICACIÓN } \\
\text { PARCIAL }\end{array}$} & \multirow{2}{*}{$\begin{array}{l}\text { TOTAL DED. } \\
\text { PARCIAL }\end{array}$} \\
\hline & & $\mathrm{F}$ & M & & $\mathrm{F}$ & M & \\
\hline FACULTAD DE ARQUITECTURA & 157 & 5 & 18 & 23 & 27 & 107 & 134 \\
\hline FAC. DE BIOQUIMICA Y FARMACIA & 35 & 9 & 3 & 12 & 11 & 12 & 23 \\
\hline FAC. DE ODONTOLOGÍA & 97 & 5 & 3 & 8 & 46 & 43 & 89 \\
\hline $\begin{array}{l}\text { FAC. DE CIENCIAS JURIDICAS Y } \\
\text { POLÍTICAS }\end{array}$ & 164 & 3 & 11 & 14 & 49 & 101 & 150 \\
\hline FAC. DE MEDICINA & 301 & 10 & 13 & 23 & 114 & 164 & 278 \\
\hline CARRERA DE ENFERMERÍA & 41 & 2 & 0 & 2 & 27 & 12 & 39 \\
\hline $\begin{array}{l}\text { FAC. DE DESARROLLLO RURAL Y } \\
\text { TERRITORIAL }\end{array}$ & 26 & 0 & 10 & 10 & 1 & 15 & 16 \\
\hline FAC. DE CS. AGRÍCOLAS Y PECUARIAS & 99 & 14 & 48 & 62 & 8 & 29 & 37 \\
\hline FAC. POLITÉCNICAS DEL VALLE ALTO & 45 & 2 & 5 & 7 & 9 & 29 & 38 \\
\hline $\begin{array}{l}\text { FAC. HUMANIDADES Y CS. DE LA } \\
\text { EDUCACIÓN }\end{array}$ & 167 & 11 & 15 & 26 & 67 & 74 & 141 \\
\hline FAC. DE CIENCIAS ECONÓMICAS & 181 & 6 & 21 & 27 & 31 & 123 & 154 \\
\hline FAC. DE CIENCIAS Y TECNOLOGÍAS & 295 & 41 & 84 & 125 & 24 & 146 & 170 \\
\hline FAC. DE CIENCIAS SOCIALES & 35 & 1 & 2 & 3 & 6 & 26 & 32 \\
\hline FAC. DE VETERINARIA Y ZOOTECNIA & 24 & 0 & 5 & 5 & 5 & 14 & 19 \\
\hline
\end{tabular}

De las 14 facultades -incluida la carrera de Enfermería- 11 de ellas están conformadas mayoritariamente por hombres y solo las tres restantes están constituidas mayormente por docentes mujeres.

Para completar este marco de inequidades, las mujeres estuvieron ausentes en los procesos electorales como candidatas a los puestos de Rector y Vicerrector, salvo dos excepciones puntuales, la PhD. Elena Ferrufino y la Dra. Mercedes Albornoz que rompen con esta tradición androcéntrica institucional de la UMSS postulándose como candidatas en puestos máximos de poder durante las elecciones de 2016. Si bien en la actualidad existe cierto incremento del número de mujeres en cargos jerárquicos o políticos dentro de la UMSS, por ejemplo ya existen decanas en algunas facultades, aún no hay una representación ni muchos menos igualitaria en los consejos de carrera, facultativos y universitario. Esta radiografía institucional androcéntrica se agudiza aún más con la prevalencia de la dominación masculina dentro de las relaciones de poder donde las mujeres intentan difícilmente derrumbar barreras y abrirse camino.

El género representa también una forma de relación de poder entre dos individuos diferentes entre los que tiende a establecerse una relación asimétrica. A decir de Scott (1996), el género es un elemento constitutivo de las relaciones sociales basadas en las diferencias que distinguen los sexos y es una forma primaria de relaciones significantes de poder, y Foucault (1978, p. 156) define «el poder como multiplicidad de relaciones de fuerza inmanentes al dominio en el que se inscriben". 
Las relaciones de poder son el instrumento, la armazón de una institución y se extienden como nervio neurálgico en el entramado universitario. En esta red molecular de poder se definen dos grupos: el constituido por los que no aceptan formar parte de él, que «aceptan ser sometidos» y los que sí aceptan ser parte, que está constituido por quienes elaboran las «normas» para establecer las relaciones de sometimiento.

Hablar de género y de relaciones de género, ya sea a escala micro o macro, conlleva a establecer conceptualizaciones acerca de los roles y funciones del hombre y de la mujer; mediante este ejercicio se logra identificar y comprender ideas, creencias, discursos y prácticas diferenciales según los sexos que los individuos realizan de manera naturalizada e institucionalizada como resultado del ejercicio del poder. En este sentido, rescatamos el planteamiento de Bordieu y Passeron $(2001 ; 2009)$ que sostienen que el habitus es el resultado de una serie de factores: familiares, sociales, los recursos económicos y culturales de los que se dispone junto a la experiencia vital, y las relaciones con las instituciones y con otras personas, que conllevan una serie de patrones de comportamiento. Este proceso de «inculcación» se realiza principalmente en la familia (socialización primaria), en la educación formal y a través de los medios de comunicación (socialización secundaria).

Bourdieu ha expuesto dinámicas estructurales de las relaciones jerárquicamente diferenciadas en los agentes de saber-poder gobernados por los académicos universitarios $y$, aunque no hace referencia explícita a la participación de las mujeres en estas dinámicas o relaciones, su planteamiento es perfectamente aplicable al ejercicio de poder entre géneros en el ámbito universitario:

Lo que puede aparecer como una suerte de defensa colectiva y organizada del cuerpo profesoral no es otra cosa que el resultado adicionado de millares de estrategias de reproducción independientes, y sin embargo orquestadas; de millares de acciones que contribuyen efectivamente a la conservación del cuerpo porque son el producto de esa suerte de instinto social de conservación que es el habitus dominante (Bourdieu, 2008, p. 196).

La universidad es un espacio complejo donde existen subespacios como el académico, científico y el de la gobernabilidad universitaria en los cuales se entretejen espacios de poder con dos grupos claramente definidos, los «oprimidos y los opresores». Esta realidad es reflejada por una docente:

El problema es que hay una cultura, Ilamémosla así, politiquera, que es muy difícil de romper. Es una estructura que más allá que esté uno u otro en el gobierno en sus distintos niveles universitarios, facultativos, de carrera, no importa quién esté; igual funciona, y funciona así, o sea mal. No importa quién esté, es una especie de cultura política, burocrática, administrativa, etc., que parece que las cosas funcionan así, y con el pasar de los años eso es lo grave, que se va institucionalizando, en el peor sentido de la palabra. Lo que debería ser anormal, se vuelve normal (Doc. Exp. 028).

Con base en este marco, el objetivo general del estudio es comprender y analizar de qué forma las relaciones de poder generan mecanismos de inclusión, exclusión y resistencias que experimentan los y las docentes en las prácticas de formación, investigación y políticas de gobernabilidad universitaria en la Universidad Estatal Mayor de San Simón. A partir del objetivo general, se plantean los siguientes objetivos específicos:

- Determinar cuáles son las relaciones de poder que experimentan las y los docentes en sus prácticas de formación, investigación o políticas de gobernabilidad universitaria.

- Identificar los mecanismos de inclusión generados por las relaciones de poder que experimentan las y los docentes en las prácticas de formación, investigación o políticas de gobernabilidad universitaria.

- Establecer los mecanismos de exclusión producidos por las relaciones de poder que experimentan las y los docentes en las prácticas de formación, investigación o políticas de gobernabilidad universitaria.

- Desentrañar las resistencias generadas por las relaciones de poder que experimentan las y los docentes en las prácticas de formación, investigación o políticas de gobernabilidad universitaria. 


\section{Metodología}

Se adoptó el enfoque metodológico cualitativo que permite recrear en la interacción social y simbólica ensamblando la voz de los actores. El análisis, de corte hermenéutico interpretativo e inductivo, fue instrumentalizado a partir de los postulados metodológicos de la Teoría fundamentada de Strauss y Corbin (2002), cuyo objetivo es que la teoría emerja a partir de los datos.

\section{Muestra}

La muestra tiene un carácter intencional no probabilístico, propio de las investigaciones de corte cualitativo. Se han realizado un total de 80 entrevistas en profundidad: 40 entrevistas a docentes expertos (20 mujeres y 20 hombres) y 40 a autoridades universitarias que ejercieron algún cargo directivo durante los años 2015 y 2017 (21 mujeres y 19 de hombres) y que tienen una antigüedad de 10 a 15 años en la institución.

\section{Instrumentos}

Se ha diseñado una guía semiestructurada de entrevistas a profundidad para docentes y docentes expertos, y cuadros de observación para el registro etnográfico en las sesiones de los Honorables Consejos Facultativos de la Facultad de Humanidades y Ciencias de la Educación. La finalidad de ambos instrumentos es observar y analizar cómo las relaciones de poder generan mecanismos de inclusión, exclusión y resistencias en los y las docentes en sus prácticas cotidianas de formación, investigación o políticas de gobernabilidad universitaria.

La guía semiestructurada en profundidad para docentes y expertos universitarios está constituida por 15 cuestiones. El instrumento fue sometido a la validación previa, habiendo sido aplicada a un grupo compuesto por 10 docentes pertenecientes a la Facultad de Humanidades y Ciencias de la Educación quienes efectuaron puntualizaciones, correcciones y sugerencias en referencia a las interrogantes planteadas las cuales fueron incorporadas en la versión final del instrumento.

Asimismo se realizaron 15 registros etnográficos en sesiones ordinarias y extraordinarias de los Honorables
Consejos Facultativos de la Facultad de Humanidades y Ciencias de la Educación durante los meses de mayo, julio y agosto de 2017. Cada sesión tuvo una duración media de 5.5 horas, haciendo un total de 82.5 horas de registro de datos. La estructuración de la guía de observación tuvo tres componentes: la descripción de los sucesos, las conjeturas emergentes y los cuestionamientos sobre los datos, que fueron plasmados en el cuaderno o diario de campo.

\section{Procedimiento}

Una vez diseñado el estudio, para la aplicación de las entrevistas se invitó al profesorado de la Facultad de Humanidades y Ciencias de la Educación que tuviera una antigüedad de 10 o más años en el puesto, y a las autoridades universitarias del mismo centro a quienes se les hizo conocer los objetivos de la investigación. Posteriormente se procedió a realizar encuentros previamente concertados. Antes de realizar la entrevista se solicitó la autorización correspondiente del profesorado participante en el estudio para el registro de los datos, información que se recogió a través del uso de una grabadora. Asimismo, se solicitaron y obtuvieron los permisos correspondientes a la dirección del Honorable Consejo Facultativo para asistir y realizar los registros en una guía de observación.

Concluida la fase de recolección de información, se realizó el procesamiento analítico y sistemático a través de la selección, codificación y categorización de datos, siguiendo la estructura de Miles \& Huberman (1994), concordante con los postulados de la Teoría fundamentada de Strauss \& Corbin (2002). Las narrativas de las entrevistas fueron analizadas desde la perspectiva de Olesen (2011) con la siguiente secuencia sistematizada de acciones: reducción de datos, extracción de datos y verificación de conclusiones. Una vez obtenidos los registros etnográficos en las sesiones de los Honorables Consejos Facultativos y las narrativas de las entrevistas a profundidad se efectuó una primera lectura de estas para construir un sistema de códigos y proceder al análisis con la ayuda del programa informático In Vivo (versión 10.0). Se realizó el proceso de codificación abierta, axial y selectiva con el fin de desarrollar la interpretación de todo lo observado y registrado, mostrando interconexiones entre los datos y la posibilidad de vincularlos para elaborar diagramas conceptuales de relaciones verticales y horizontales entre ellos. 


\section{Resultados y discusión}

A continuación se exponen los resultados referidos a los códigos inferenciales según las entrevistas y etnografías analizadas. En el proceso de codificación emergen un total de tres categorías: mecanismos de inclusión, mecanismos de exclusión y mecanismos de resistencia. La primera categoría está constituida por un código, la segunda por cuatro códigos y la tercera por dos códigos, como se refleja en la Tabla 2.

\section{Tabla 2. Sistema de categorías y códigos}

\begin{tabular}{|l|l|l|}
\hline $\begin{array}{l}\text { Primera categoría: } \\
\text { Inclusión }\end{array}$ & $\begin{array}{l}\text { Segunda categoría: } \\
\text { Exclusión }\end{array}$ & $\begin{array}{l}\text { Tercera categoría: } \\
\text { Resistencias }\end{array}$ \\
\hline 1.1. Juego de la construcción de imperios & 2.1. Juego de los candidatos estratégicos & 3.1. Juego de la hegemonía \\
\hline & 2.2. Juego del soplo & 3.2. Juego del contraataque \\
\hline & 2.3. Juego de la autoeliminación & \\
\hline & 2.4. Juego de roles multifuncionales & \\
\hline
\end{tabular}

\section{Primera categoría: Inclusión}

En esta categoría se efectúa el análisis de los mecanismos de inclusión que se entretejen a través de los denominados juegos de poder en las prácticas de formación, investigación 0 políticas de gobernabilidad universitaria. Se recoge el código: 1.1. Juego de la construcción de imperios.

\subsection{Juego de la construcción de imperios}

En el interior de la universidad se despliegan las redes de poder que determinan este tipo de juegos; el cúmulo de las posiciones controladas es la condición para los intercambios entre los poderosos y sus adeptos, permitiéndoles así mantener dominio en el tejido institucional. Esta construcción de imperios se basa en una cultura androcéntrica donde normalmente las mujeres se encuentran en la base y ellos en la cúspide de la estructura piramidal de las relaciones de poder. Así se refleja en la siguiente narrativa de una profesora:

Es impensable que nosotras las mujeres lleguemos al poder en la vida institucional de esta universidad. Hasta ahora no ha habido ninguna Rectora mujer en el país porque este mundo de la academia, de la ciencia y del poder es de ellos. Cuando nosotras queremos acceder a estos espacios nos ponen un montón de obstáculos, y si logramos perforar este "sistema de hombres" y ocupamos los puestos tan ansiados que ellos querían tener y accedemos a puestos directivos altos y medios nos hostigan para que estemos supeditadas a sus decisiones. Si no lo hacemos, nos hacen la vida imposible (Doc. Exp. 015).

La instrumentalización del poder, por parte del profesorado femenino, se halla sujeta a las microdesigualdades por el imaginario cultural y simbólico de la multifuncionalidad que las mujeres están llamadas a cumplir.

\section{Segunda categoría: Exclusión}

Esta categoría ha resultado ser la más prolífica y está constituida por cuatro códigos: 2.1. Juego de los candidatos estratégicos; 2.2. Juego del soplo; 2.3. Juego de la autoeliminación; y 2.4. Juego de los roles multifuncionales.

\subsection{Juego de los candidatos estratégicos}

En las estrategias de reproducción lo que aparece como una suerte de defensa colectiva y organizada del cuerpo 
profesoral no es más que el resultado de intenciones múltiples que se decantan en decisiones colectivas orquestadas por los intereses de grupo. Así, por ejemplo, en la selección de docentes para ciertos cargos, los hombres son quienes cartografían las decisiones sin importar que las mujeres que aspiran a ocupar cargos directivos tengan las competencias y preparación para ejercer dichos puestos. Las presiones políticas afectan la actuación de los sujetos de forma desmedida, incluso más allá de lo que concierne el espacio institucional. Una docente señala:

Para ser candidato a Rector y Vicerrector tienes que ser hombre porque para ellos, además que son la mayoría, es impensable que una mujer no les dé órdenes. A pesar de que las condiciones en la academia se han aperturado, pues tenemos más horas de clases, esto no ha sucedido a nivel de la gobernabilidad, porque siguen mandando ellos. La política androcéntrica los lleva a pensar que nosotras las mujeres no podemos desempeñarnos en altos puestos directivos porque creen que tenemos medio cerebro en la casa y la otra parte en la universidad. Ellos siempre dicen: "no vamos a permitir que nos vengan a mandar las mujeres; en el gallinero, el gallo manda" (Doc. Exp. 007).

De lo que se colige que en el espacio de Educación Superior sansimonense las ataduras de los imaginarios androcéntricos se extienden como la segunda piel en las prácticas académicas, científicas y de gobernabilidad universitaria. Para que un docente pueda ser candidato estratégico debe pertenecer a un grupo de poder a lo que se agrega la determinante del género, dicotomía que catapulta a la mujer en los espacios de poder dejándola fuera del juego.

\subsection{Juego del soplo}

El cuerpo docente se halla sujeto a la aceptación de los límites políticos asignados por la institución, que les confiere garantías estatutarias ligadas al statu quo donde la innovación y la invención intelectual, así como la libertad y el espíritu crítico, han sido relegados a un segundo plano.

El sistema político pone en tensión constante a los profesionales docentes y los empuja a inclinarse hacia un partido político; encajar o no en los esquemas e ideologías de poder universitario es una decisión que ningún docente puede eludir. La díada retórica de «o te alineas o estás fuera» cobra capital importancia en las prácticas de formación, investigación y gobernabilidad universitaria. En este contexto político-académico, en el entramado del poder se entretejen microviolencias institucionales que afectan a las académicas:

Cuando tú estas peleando en el plano político y ellos ven que tu propuesta es la mejor y estás luchando por algo que es coherente, y estás a punto de ganarles, entonces se saltan al plano personal, te dicen: ¿eres casada?... Te están viendo con tu anillo en la mano y te preguntan si eres casada, y por ahí van sus chistes, poco más te preguntan ¿y tu marido te satisface?, ¿por qué estás peleando así? O cuando vas a una reunión -yo soy Decana-... y cuando voy a esas reuniones de puros hombres, y somos apenas 203 mujeres, te silban cuando entras, te dicen: qué linda tu falda, qué sexy estás, te queda bien ese labial y demás, todo con el objetivo de anularte como académica y autoridad mujer (Doc. Exp. 009).

Las mujeres que se hallan en cargos directivos son objeto del chiste y la burla para ser anuladas, es decir, su oponente las destruye para que no representen ningún tipo de amenaza.

\subsection{Juegos de autoeliminación}

Si bien se identifican, en el estudio, narrativas que destacan la adjudicación del poder masculino a partir del cual se ejercen diversos mecanismos de control y prevalencia de su estatus de dominación, se percibe cierta resistencia de las académicas a asumir el poder por temor a que en el desempeño de sus funciones en los puestos de decisión reciban el rechazo o los reproches de parte de los docentes, ya que ellas están dispuestas a imponer una «sumisión forzada» que se volcaría contra ellas mismas. Una docente titular, defensora del cambio institucional responde:

[¿Usted estaría dispuesta a acceder a cargos de gobernabilidad como decana, como directora académica, al instituto de investigaciones?]

¡No!, porque me haría de enemigos... Porque yo controlaría, yo lo controlaría y cambiaría todo; no permitiría que nadie firme y se vaya permanentemente sin trabajar, como ocurre ahora (Doc. 007).

Scott (1996) sostiene que la sumisión forzada podría producir una reacción en contra de dichas actitudes, por 
lo que es posible que los subordinados hicieran notar el discurso oculto de manera más efusiva y constante.

Las docentes, mayoritariamente, rechazan el sistema institucional actual, pero a pesar de que se reconocen como un agente diferente al resto y como un recurso humano rescatable, no están por la labor de hacer nada para cambiar la realidad. De esta manera, asumen una posición pasiva consintiendo la estructura establecida, reforzando indirectamente el sistema hegemónico androcéntrico. Se autodescarta o autoexcluye, aun sabiendo que tiene las competencias necesarias para promover transformaciones desde el ejercicio del poder. Un profesor sostiene:

Muchas veces las mujeres se autodescartan. Se autocensuran, se descartan, no se atreven; saben de su capacidad y no la ejercen; entonces me parece que es importante en qué lugar se pone una mujer, y cómo sostiene un liderazgo (Doc. 037).

Pareciera que, en general, las docentes, aunque saben que hay que resolver los problemas de la universidad y que ellas podrían contribuir positivamente en este proceso, se mantienen al margen para no tener que asumir todo lo que ello conlleva. Una docente comenta:

Nonos metemos porque tener un puesto en la universidad implica muchas cosas... no solo responsabilidad, sino tiempo, esfuerzo, críticas, problemas personales, familiares, emocionales... (Doc. 011).

Asimismo, el poder como fuerza esencialmente represora es utilizada, en ocasiones, por su mismo género para volcarse contra sí misma y este hecho motiva su autoexclusión; es decir que son las propias mujeres quienes imposibilitan o dificultan el ejercicio del poder entre y para con su género. Algo que me ha sorprendido es que entre las mujeres no hay solidaridades ¿no?... Son las mismas prácticas masculinas de empoderamiento, de exclusión, de luchas, competencias desleales ¿no?, entre mujeres, ientre mujeres!, cuando a veces nosotras hablamos que las mujeres deberíamos estar juntas, para otras reivindicaciones más de nuestro género ¿no es así? No hay esa unidad, o sea eso he visto ¿no? Peleas entre mujeres pero ipeor que hombres!, porque el hombre de hecho es prepotente, todo ¿no?: Peor entonces, para qué me voy a atrever (Doc. 003).
Otra forma de exclusión se produce en el trato diario, en las actitudes de rechazo, en los gestos, en el tono de voz, en la negación del ser mismo como autoridad, una especie de falta de reconocimiento de lo que se es; esto es, que por el hecho de ser mujer no se reconoce la autoridad de las docentes; entonces el agente de poder «flaquea" y se producen grietas que los subordinados aprovechan para actuar contra el ejercicio del poder de la mujer.

No, directamente ellos te niegan. No existes como directora, no eres la autoridad, te anulan, ni te consultan, has muerto en ese periodo que ejerces el cargo y después ya eres menos persona digamos; los colegas hombres te quitan mérito [...] (Doc. 032).

Esta realidad concuerda con los postulados de Foucault (1978, p. 119) cuando señalaba que «el poder en su ejercicio va mucho más lejos, pasa por canales mucho más finos y es mucho más ambiguo». Las redes de la dominación y los circuitos de la explotación se interfieren, se superponen y se refuerzan.

\subsection{Juegos de roles multifuncionales}

Se arguye, desde el constructo bourdieuriano (1977), que los mecanismos de exclusión a la mujer por parte de sus pares docentes funcionan como una guerra continua y silenciosa, expresando formas de violencia simbólica y sexual que van en desmedro de lo femenino. Dos docentes de la UMSS sostienen:

Pero si, digamos, una mujer participa en la política, fácilmente le panfletean sobre su familia y sobre sus cosas, su vida personal, que es una puta y todo eso, que es como un chantaje para que no ocupe cargos, entonces "le buscan su cola de paja que no tiene"; hacen lo posible e imposible para que no suba porque es mujer (Doc. 017).

Si una mujer se postula para cualquier cargo, no hablan o dicen sobre temas de corrupción... más que todo hablan de sus asuntos personales, ¿no es cierto?... Cuando quieren atacar a una mujer que está en un cargo de dirección, se van a hablar cosas personales ¿no?, no hablan tanto de temas técnicos, académicos ¿no? Si quieren atacarla lo hacen de una forma más personal (Doc. 010). 
También existen formas de microviolencia manifiesta en contra de las mujeres a través de mensajes simbólicos que mellan la dignidad y la privacidad de la mujer. Como argumenta Scott (1996), resulta difícil de imaginar a la mujer separada de sus vínculos familiares y roles maternales, por ello se la ataca allí, donde más le impacta lo negativo.

Las mujeres son sujeto de una violencia simbólica de manera más intensa que los varones; claro que sí. Volvamos al tema por ejemplo de los cargos públicos, los cargos del poder universitario; entonces, las colegas docentes son motivo a veces de este tipo de violencia verbal; sobre todo esta suerte de acoso, un poco subrepticio de parte de los varones. Estoy seguro que ellas sienten temor y es una razón que puede inhibir su participación plena en estos cargos (Doc. 030).

Una decana con una amplia experiencia en la gestión de relaciones de poder y resolución de problemas y conflictos políticos sostiene:

Sí, existe una posición machista que se expresa en algunos comentarios a veces desagradables; por ejemplo, si tú estás peleando por lo que crees que son reivindicaciones desde tu facultad, dicen "iAy!, por qué estás molestando tanto... ¿estás casada?", le ponen una connotación sexual a la cuestión o sea, como que "te está haciendo falta algo" o sea, "¿qué tienes?" Entonces como que todavía hay ese tipo de situaciones frente al liderazgo que puedan ejercer las mujeres y eso no se puede negar, entonces hay una violencia verbal; pero también hay una violencia simbólica con relación al género que tú representas (Doc. 028).

Todo ello refleja lo manifestado por el filósofo francés, que sostenía que «en las relaciones de poder, la sexualidad no es un elemento sordo, sino uno de los que están dotados de mayor instrumentalidad: utilizable para el mayor número de maniobras y capaz de servir de apoyo y bisagra a las más variadas estrategias» (Foucault, 1999, p. 122).

Siguiendo la hilaridad del análisis, se puede afirmar que las académicas aún están sumidas dentro del entramado social de prácticas y discursos culturales arbitrarios de género, con ideologías individuales y colectivas que asignan roles estereotipados de mujer-esposa-madre-profesional-ama de casa:
Se estaba decidiendo quién sería el próximo director de carrera y, ellos se cerraban y me decían "no hay nadie más, tienes que ser tú", yo no puedo ser, "¿no, por qué?" me cuestionaban, "¿por qué no puedes ser después de tantos años de haberte esforzado y dedicado y que tienes el perfil adecuado?"... y "tiene que ser", entonces yo expliqué: miren yo tengo una hija pequeña y mi esposo no me va a permitir, "bueno; por último si no te deja, tienes que dejarlo, ipara eso existe el divorcio! [...] entonces yo les dije: voy a tratar de conversar con él y explicarle que tiene que ser así (Doc. 004).

Estas percepciones coinciden con la dinámica relacional del sistema familiar y profesional como una fusión de lo público y privado. Algunos docentes tienen percepciones similares al respecto:

Hay colegas mujeres que trabajan en mi carrera y que todo el tiempo andan mencionando: " $i U y$ ! ya es tarde, tengo que irme, mi esposo me va a reñir" o "qué voy a hacer, el trabajo me ocupa mucho tiempo. No sé qué hacer, se molesta mucho mi esposo" (Doc. 007).

Dado que el poder, en el contexto universitario, no puede ser acumulado y mantenido sino al precio de un gasto constante e importante de tiempo, es tendenciosa la autoexclusión de las mismas mujeres docentes que limitan su desarrollo profesional a la red familiar que ejercen tensión sobre ella y generan un estado de malestar continuo que les lleva a dedicar «solo el tiempo necesario dentro de la universidad». El dedicar más tiempo a la universidad significa para ellas restar tiempo a su familia o pareja; entonces, algunas mujeres que tienen expectativas de ejercer algún puesto de responsabilidad se encuentran con un dilema, aunque generalmente terminan priorizando la familia. Así, por influencia de su entorno familiar y social, y por la forma en que la mujer ha sido educada, los problemas y tensiones domésticos terminan prevaleciendo e imponiéndose sobre las aspiraciones académicas y profesionales de las académicas.

La afirmación de De Barbieri (1991, p. 204) que arguye que «el hogar es lugar de descanso, ocio, no trabajo» ha quedado en entredicho; por el contrario, el hogar es un lugar con un sinfín de actividades que requiere de tiempo y energía. Esta situación de demanda continua del hogar es utilizada 
estratégicamente por la academia y, en consecuencia, se prefiere seleccionar a personas que se encuentren menos ligados a estas «demandas distractivas o hasta quizás perjudiciales». Por ello, también se muestra una diferencia para hombres y mujeres en cuanto a la accesibilidad a becas de estudio para los doctorados, desfavorable para las mujeres, debido a factores que tienen que ver con su vida privada familiar y favorable para los hombres porque ellos no muestran tanta «dependencia del hogar».

Para las postulaciones te dicen que más bien debería haber una discriminación positiva de género para los doctorantes y maestrantes mujeres, pero la verdad es que no es así; te dejan ir a la maestría, pero para el doctorado ya no te dan la posibilidad. Te ponen muchas trabas, por ejemplo, especialmente si eres madre, si eres madre soltera peor, sí también la edad y otras cosas que te ponen trabas y a los hombres no les ponen, ni se considera esas cosas (Doc. 040).

¿Por qué se entiende el ejercicio del poder como una forma de relación eminentemente masculina? Quizás la respuesta consecuente es que las mujeres no suelen ocupar espacios de poder jerarquizados porque ello les restaría tiempo que suelen y «deben» dedicar a su hogar y a su familia. Se sabe que el trabajo dentro del hogar exige una constante respuesta de atención a las necesidades y este rol ha sido asignado sociohistóricamente a la mujer. Entonces, lo que hace ella es «acomodar sus actividades» y sus decisiones profesionales e institucionales en función de su vida familiar:

Las mujeres fuera de ejercer la docencia o ejercer una autoridad, tienen también funciones en la familia, en el hogar etc., probablemente, por esto, tienen limitaciones y restricciones. No es como el hombre que tiene más libertad que la mujer, probablemente ese sea un factor. Otro factor también debe ser la mujer no haya aceptado el desafío, el reto de participar en política, por que la política y la lucha por el poder a veces demasiado encarnizada, demasiado apasionada y afectan hasta identidades, dignidades, la vida privada de las personas. Probablemente la mujer no ha tenido mejores oportunidades de involucrarse en la política, por eso es que no ha logrado sitiales tan importantes como el nivel de rector, de vicerrector, etc. (Doc. 024).

Empero, existen casos aislados de mujeres más independientes de su hogar, que además de esas demandas de la vida privada, ejercen el poder como una acción de cambio y transformación de la realidad:

Es una situación que se da permanentemente "no, mejor no me meto, mejor no digo nada, mejor me voy" y eso no está bien; yo creo que las mujeres debemos tener la voluntad de decirlo, de hacer conocer que no estamos cómodas. (Doc. 020).

Frente a los conflictos y tensiones políticas y relaciones de poder que se entremezclan y sobreponen a las actividades académicas, unido a los estereotipos de género y al desempeño de roles tradicionalmente asociados a la mujer, las académicas deciden mantenerse distantes; de esta manera se sitúan en una posición subordinada por los agentes del poder, marcando con su silencio una línea favorable de acción para ellos. El rechazo a las formas políticas se manifiesta un aparente "quemeimportismo» que lo que hace es mantener la hegemonía del poder androcéntrico.

\section{Tercera categoría: Resistencias}

El ensamblaje de la voz de los actores con referencia a las resistencias de las docentes en las prácticas académicas, científicas o políticas de gobernabilidad universitaria han sido analizadas con dos códigos: 3.1. Juegos hegemónicos; 3.2. Juego del contraataque.

\subsection{Juegos hegemónicos}

Las relaciones sociales se han ido marcando por diferencias en cuanto a roles, funciones, expectativas e imaginarios específicos para cada género y, dentro de estos habitus, como disposiciones subjetivas que dirigen pensamientos y prácticas condicionadas a la ideología dominante, donde la mujer se encuentra como un agente «limitado» de poder, como un ser presumiblemente «incapaz» de destacar en el ámbito público o profesional. A partir de las narrativas se desprende que las docentes tienen que superar obstáculos en el ejercicio de cargos jerárquicos. Esta forma de representación social del imaginario es puesta de manifiesto por las académicas:

Sí, sí, sí, hay muchos estereotipos de género... Una cosa general de nosotros es la minusvaloración de ellas y esa minusvaloración está también en las propias mujeres. Durante mucho tiempo nuestras compañeras se han valido de algo, de alguien para hacer lo que querían hacer o ser (Doc. 019). 
Se hace referencia a una posición de sumisión de la mujer respecto al hombre, que la condiciona a estar por detrás en su desempeño cotidiano. Esta posición de subordinación, que es rechazada y desaprobada, se denota incluso dentro de mecanismos de inclusión en la que si bien ella ha alcanzado algún puesto de poder, ellos tienen la hegemonía.

Yo he tenido la oportunidad de ver hombres y mujeres trabajando casi en igualdad de condiciones, pero claramente persiste la mentalidad de los hombres. Es "difícil reconocer que las mujeres hayan avanzado", hayan logrado incluso niveles mucho mayores al hombre porque al final son ellos los que deciden (Doc. 024).

Bourdieu (1991) ya había abordado la conservación del habitus dominante; la existencia de dinámicas estructurales de las relaciones jerárquicamente diferenciadas en los agentes de saber-poder gobernados por los académicos universitarios y aunque no hacía referencia explícita a la participación de las mujeres en estas dinámicas o relaciones, el planteamiento se puede aplicar al caso que nos ocupa. El habitus dominante de preservación hegemónica masculina confluye en diversos intentos de conservación dentro del estamento docente de la universidad boliviana.

La discriminación, como una fuerza de poder, se inserta de modo casi cotidiano en el comportamiento natural de algunas personas en la academia, que la instauran mediante formas de marginación subrepticia en gestos, actitudes y frases disfrazadas en el chiste, las indirectas, como un discurso oculto emergente que es identificado por quienes han visto o vivenciado esta forma de relación de poder:

Ahora, en mi trayectoria académica, digamos, por ejemplo, sí he visto que hay mucha discriminación, porque si eres joven, mujer y peor, no ingeniera, entonces resulta de que por algo debe estar ahí... "que no sabes por qué" (Doc. 017).

Esta hegemonía masculina se observa también en la división del trabajo; pese a las transformaciones y cambios, se ha redefinido sobre la base de la descalificación de las ocupaciones femeninas o que se feminizan.

Trabajé un tiempo en agronomía, pero cuando quise introducir el enfoque intercultural en la formación de los ingenieros agrónomos, casi me choqué con la pared porque realmente era una visión totalmente monocultural, tecnócrata y machista, machista... Porque cuando yo era docente, los ingenieros decían: "Las coleguitas que sirvan el café y nosotros vamos a hacer el plan operativo" (Doc. 003).

Con esto, se aprecia cómo el poder-saber masculino halla sustento en el entramado social como discurso hegemónico en el cual el género femenino suele ocupar una posición de subordinación porque, según este, la mujer no termina de encajar en ese saber y tiene además una forma diferente de ser y hacer, por lo que es rechazada también a través de mecanismos de exclusión en espacios de acción y decisión. Sin duda, a partir de ello se pueden plantear diversas respuestas, actitudes y acciones contestatarias, porque iacaso la solución es adaptarse al saber y saber hacer androcéntrico? Las respuestas estarán condicionadas por la subjetividad individual tanto de las docentes como de los docentes.

\subsection{Juego del contraataque}

El poder no se remite simplemente al dominio de unos sobre otros; en su actuación, este es mucho más fino y transita por intersticios a través del contraataque.

A partir de los hallazgos, se identifica una lucha de poder entre los y las docentes, una suerte de cotraataque semioculto que dirige ciertas conductas en contra de las académicas. Estas se evidencian en múltiples formas de microviolencias que se van generando con el fin de mantener cierto espacio de poder dentro de la universidad. Esta microviolencia o violencia simbólica se realiza a través de reclamos familiares, ajenos al campo propiamente académico, o mediante el intento de instaurar una «ideología del deber» de las mujeres, por ejemplo el papel de madre y esposa antes que el de ser académica:

Haremos otras cosas, vamos a pasear, vamos a farrear, vamos a hacer esto, vamos a hacer lo otro, que las wawas, que no sé qué, siempre era el mensaje de menor tiempo al trabajo y más tiempo a la familia. Entiendo que la familia es importante, pero también están tus prioridades personales, entonces ha sido una fuerte tensión, ha sido una fuerte tensión [...]. Es que los reclamos eran por competencia, como él es docente también aquí, era por competencia, era como que la sensación de que yo estaba haciendo más y él no estaba haciendo nada. Entonces se creaban rivalidades, 
y los reclamos se hacían a través de las wawas, que te dicen que no les dedicas tiempo, que nunca estás, y si estás, te encierras en tu estudio (Doc. 008)

Existe una disputa constante por la efectivización de los mandatos culturales androcéntricos; las tensiones dentro del entorno familiar se intensifican para flanquear nuevas incursiones a nivel institucional priorizando la trilogía multifuncional que las mujeres están llamadas a cumplir: ser madre, esposa y ama de casa.

\section{Conclusiones}

A partir del desarrollo analítico de las relaciones de poder en el campo universitario, se concluye que la figura femenina se desenvuelve, en este entorno, de forma diferente que sus pares hombres en la academia y en la política, en cuanto a su representación porcentual y las características cualitativas particulares de su género. El desenvolvimiento profesional de las docentes está marcado por tres tipos de mecanismos: de inclusión, de exclusión y de resistencias, con claro predominio del segundo tipo. Los elementos que determinan el funcionamiento de estos mecanismos son la cultura organizacional androcéntrica de la universidad, el contexto familiar, y la propia subjetividad de las académicas. Se sostiene consistentemente el habitus del «deber ser mujer-esposa-madre-profesional-ama de casa» que configura la ideología vigente en el ámbito académico de la multifuncionalidad de la mujer, situación que se refleja no solo en la universidad boliviana, sino en todo el mercado laboral boliviano.

Las académicas apenas participan en el Juego de la construcción de imperios por su escasa presencia en los espacios jerárquicos, donde se erige, maneja y gestiona el poder institucional. Consecuentemente se generan relaciones asimétricas de poder, donde las docentes tienen una posición de subordinación frente a la posición hegemónica androcéntrica que da preferencia a sus pares y que relega, excluye o descalifica a la mujer en sus intentos de reivindicación.

Los mecanismos de exclusión hacia la mujer están presentes en las prácticas y discursos masculinos, pero también en los femeninos, por lo cual se concluye que son las mismas mujeres quienes en ocasiones abandonan, postergan y evaden la responsabilidad de asumir puestos de poder institucional. Se colige que estas prácticas relacionales están naturalizadas y aún son escasos los mecanismos de resistencias de las académicas. Como señalaba Foucault (1978), nada cambiará en la sociedad si no se transforman los mecanismos de poder que funcionan dentro de la cotidianidad.

En los juegos hegemónicos y del contraataque, él triunfa porque se ve favorecido por la conservación del habitus dominante y por la existencia de dinámicas estructurales de las relaciones jerárquicamente diferenciadas en los agentes de saber-poder gobernados por los académicos universitarios y por la discriminación de género que está naturalizada en la cultura universitaria, reforzada significativamente, nuevamente, por la propia autoeliminación de la propia mujer.

En suma, hay poder activo y real, propio de los hombres y otro poder pasivo y «prestado» de las mujeres, que plantea la necesidad de hacer una crítica de la posición social que ocupan hombres y mujeres, y de las valoraciones subjetivas que los individuos y los colectivos tienen acerca de las relaciones de poder en el ámbito universitario. Solo así los roles designados y aceptados apriorísticamente por el sexo correspondiente podrán tomar un giro que pueda generar consecuencias prácticas interesantes.

\section{Referencias}

Bourdieu, P. (1991). El sentido práctico. Madrid: Taurus.

Bourdieu, P. (1977). La reproducción. Elementos para una teoría del sistema de enseñanza. Barcelona: Laia.

Bourdieu, P. (2008). Homo academicus. Madrid: Siglo XXI.

Bourdieu, P., \& Passeron, J. C. (2001). La reproducción. Madrid: Popular.

Bourdieu, P., \& Passeron, J. C. (2009). Los herederos. LoS estudiantes y la cultura. Madrid: Siglo XXI.

De Barbieri, T. (1991), Los ámbitos de acción de las mujeres. Revista Mexicana de Sociología, 53(1), 203-224.

Foucault, M. (1978). Microfísica del poder. Madrid: La Piqueta. Foucault, M. (1998). Historia de la locura. Bogotá: F.C.E.

Foucault, M. (1999). Estrategias de Poder. Obras esenciales II. Barcelona: Paidós.

Miles, B., \& Huberman, A. M. (1994). Qualitative data analisis. Londres: SAGE Publications.

Olesen, V. (2011). Feminist qualitative research in the millennium's first decade. Developments, challenges, prospects (pp. 129-146). En K. Denzin, \& Y. Lincoln 
(Eds.), The SAGE handbook of qualitative research. Los Ángeles: SAGE.

Scott, J. (1996). El género: una categoría útil para el análisis histórico. En M. Lamas (Comp.), El género: la construcción cultural de la diferencia sexual (pp. 265302). México: Universidad Autónoma de México/Porrúa.
Strauss, A., \& Corbin, J. (2002). Bases de la investigación cualitativa. Técnicas y procedimientos para desarrollar la teoría fundamentada. Medellín: Universidad de Antioquia.

Universidad Mayor de San Simón (2014). Universidad en Cifras 2009. Cochabamba: Planta Gráfica de Editorial Serrano. 